\title{
Endoskopik yöntemle tedavi edilen bir duodenal duplikasyon kisti olgusu
}

\author{
Endoscopic treatment of a case of duodenal duplication cyst
}

Ismail Hakkı KALKAN, Bilge TUNÇ, Selçuk DIŞıBEYAZ, Erkin ÖZTAŞ, Erkan PARLAK, Nurgül ŞAŞMAZ

Türkiye Yüksek Ihtisas Hastanesi, Gastroenteroloji Kliniği, Ankara

Ondokuz yașında genç bayan hasta tekrarlayan karın ağrısı șikayeti ile bașvurdu. Abdominal ultrasonografi ve tomografi tetkikleri sonucunda duodenum 2. ve 3. kısimları arasinda 3 cm'lik bir duplikasyon kisti tespit edildi. $\mathrm{Bu}$ nadir hastalık için iki ayrı seansta endoskopik sfinkterotomi ve snare polipektomi yöntemleri başarı ile uyguland.

Anahtar kelimeler: Duodenal duplikasyon kisti, iğne uçlu sfinkterotom, snare polipektomi

\section{GİRISS}

Gastrointestinal (GI) trakt duplikasyon kisti, dil kökünden anüse kadar herhangi bir noktada görülebilen nadir konjenital anomalidir (1). Duodenal duplikasyon kistleri; Gi trakt duplikasyon kistlerinin en nadir görülen formudur (Tüm GI trakt duplikasyon kistlerinin \%6-7'si) (2,3). Klinikte genellikle intestinal obstrüksiyon, hemoraji veya pankreatit ile prezente olabilir, nadir olarak da enfekte olabilirler (4-6).

Erişkin yaşta nadir görülmesi ve cerrahi olmayan yöntemle başarılı bir şekilde tedavi edilmiş olması nedeniyle duplikasyon kistli olgumuzu sunmayı uygun bulduk.

\section{OLGU SUNUMU}

Ondokuz yaşında bayan hasta 1 yıldır devam eden aralıklı karın ağrısı şikayeti ile başvurdu. Olgunun ağrı şikayeti 2-3 haftada bir gelip, 12-48 saat sürüyormuş ve bulantı-kusma da eşlik ediyormuş. Bir yll önce özofagogastroduodenoskop tetkikinde antral gastrit saptanarak proton pompa inhibitörü tedavisi verilmiş, ancak hasta fayda görmemiş.

Olgunun fizik muayenesinde periumblikal ve sağ hipokondriyal hassasiyet dışında özellik saptanmadı. Laboratuvar incelenmesinde; hemograminda lökositoz (11.600/ $\mathrm{mm}^{3}$, $\mathrm{N}: 4000-10000 / \mathrm{mm}^{3}$ ), biyokimyasal incelemesinde hafif amilaz yüksekliği (220 IU/ml) dışında patolojik değer saptanmadi.

Olgunun radyolojik incelemesinde; ayakta direkt batın grafisi normaldi, abdominal ultrasonografisinde batın sağ üst kadranda duodenuma komşu, barsak peristaltizmi ile hareketli, anekoik kistik lezyon saptandı. Bunun üzerine yapılan abdo-
Nineteen years old female patient presented with a history of intermittant abdominal pain. Her abdominal ultrasonography and CT revealed a $3 \mathrm{~cm} \mathrm{du-}$ odenal duplication cyst located between second and third parts of the duodenum. Endoscopic needle knife sphincterotome and snare polypectomy methods performed succesfully at two different sessions for this rare disease.

Key words: Duplication cyst of the duodenum, needle knife sphincterotome, snare polypectomy

men bilgisayarlı tomografik incelemesinde duodenum 2-3. kıta arasında $3 \times 3 \mathrm{~cm}$ büyüklügünde kistik lezyon tespit edildi. Endoskopik incelemede duodenum 2. kıtada yerleşmiş barsak peristaltizmi ile hareketli submukozal olarak büyük bası oluşturan lezyon görüldü. Yan görüşlü duodenoskop ile de duodenum ikinci kıtada papili de içerisine alan yaklaşı 3 cm'lik kistik lezyon görüldü.

Bunun üzerine yapilan endosonografik incelemede koledoğun intraduodenal kısmı kistik biçimde genişlemiş olarak izlendi. Koledokosel olabileceği düşünüldü, ancak kistik yapının duvar katları incelendiğinde beş tabakadan oluşan duvar yapısı görülerek duplikasyon kisti olabileceği kanaatine varıldı (Şekil-1). Skleroterapi iğnesi ile girilerek kist içeriği aspire edildiğinde safra geldi (Şekil-2). Kist içerisine az miktarda kontrast madde verildiğinde pankreas kanalına geçiş izlendi. İğne uçlu sfinkterotom ile fistülotomi yapıldı. İki gün sonra yan görüşlü duodenoskop ile tekrar bakıldığında kistik yapının kollabe olduğu, geniş iki fistül oluştuğu izlendi. Histopatolojik yapısını belirlemek için kistik yapının iç kısmından biyopsi alınarak hasta bir ay sonra kontrole çağrıldı. Alınan biyopsinin incelenmesinde yer yer dejenerasyon-ülserasyon alanları ve rejeneratif tip atipi içeren düzenli yapıda duodenum mukozası tespit edildi (Şekil-3).

Kontrole gelen hastanın yakınması yoktu, hemogramı ve biyokimyasal değerleri normaldi. Yan görüşlü duodenoskop ile yapılan kontrol endoskopisinde kistik yapı küçülmüştü, koledok kanülize edilmeye çalışıldı ancak başarılı olunamadı. Kalan kistik yapıyı da küçültmek amacı ile polipektomi snare'i ile endoskopik parsiyel rezeksiyon yapıldı. Tanımızı his- 


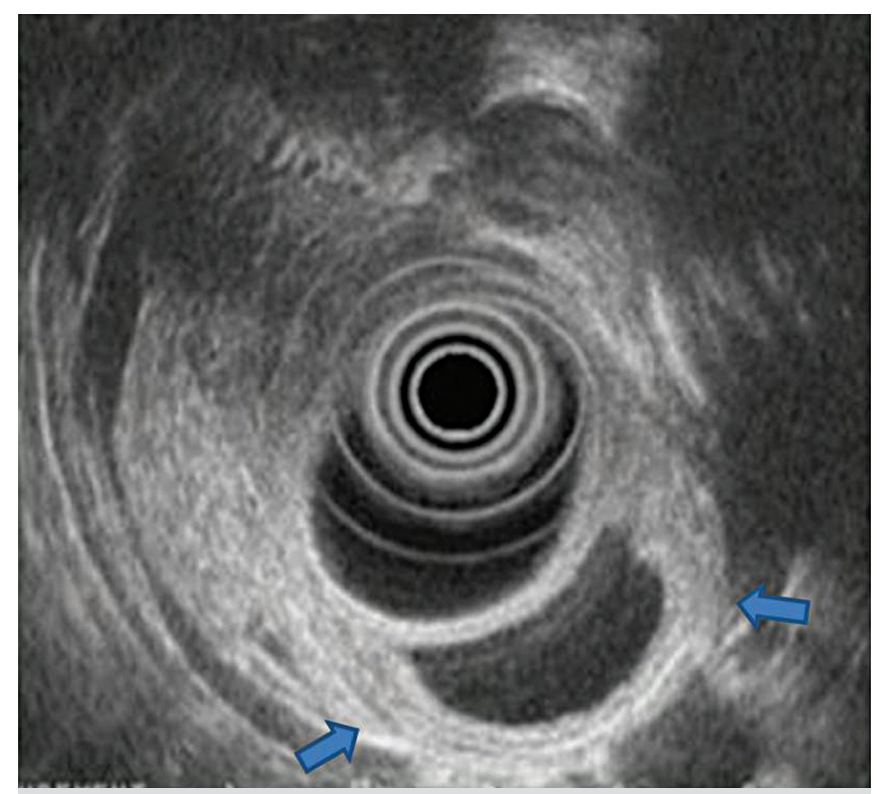

Sekil 1. Endosonografik incelemede; koledoğun intraduodenal kesiminde kistik genişleme.

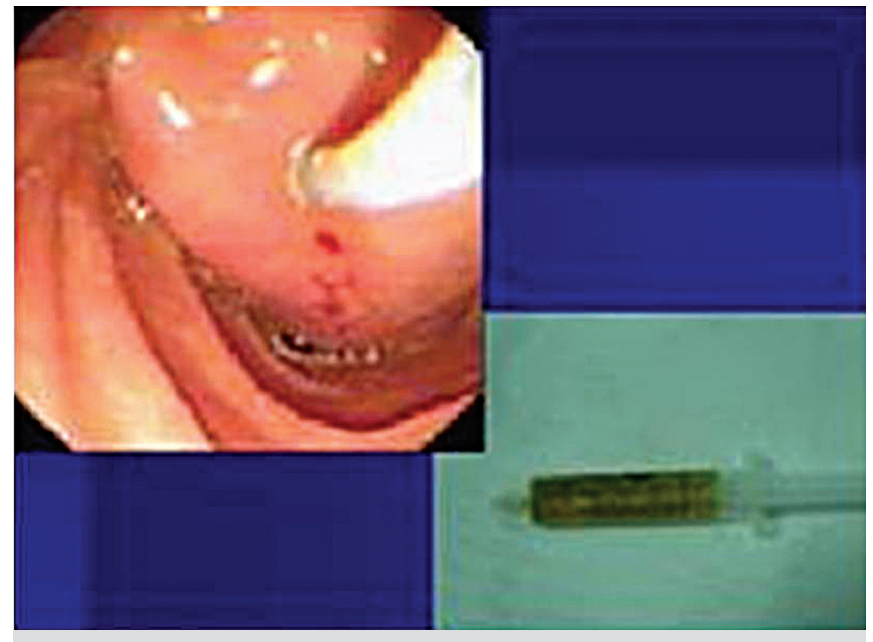

Şekil 2. Kistin aspirasyonu sonucu safra içeriği izlendi.

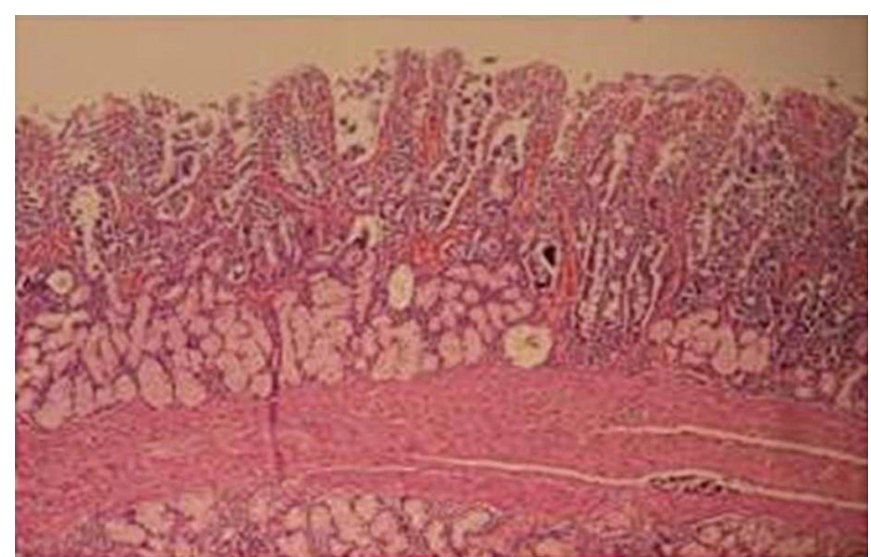

Şekil 3. Kistin iç kısmından alınan biyopside; yer yer dejenerasyon-ülserasyon alanları ve rejeneratif tip atipi içeren düzenli yapıda duodenum mukozası izlendi. topatolojik olarak doğrulamak için rezeksiyon materyali patolojik incelemeye gönderildi. Tam kat biyopsi sonucu: kistik oluşumun iç epitel yapısı düzenli yapıda duodenum mukozasından oluşmakta idi, aberan doku yoktu. Kistin dış kısmında da düzenli yapıda duodenum mukozası izlenmiş olup, muskularis propria izlenmedi, muskularis mukoza olduğu düşünülen ince kas lifleri vardı.

\section{TARTISMA}

Duplikasyon kistleri Gİ traktın nadir lezyonlarıdır. Embriyonik dönemde anormal ön-barsak gelişimi ile ilişkilidirler. Yaşamın 3.-4. haftasında primitif barsak gelişmeye başlar. Özofagus, mide, duodenum, pankreas, karaciğer ve biliyer sistem ön barsaktan gelişir (7). Genellikle infant döneminde tanısı konulsa da nadir olarak bizim olgumuzda olduğu gibi genç erişkin çağda da tespit edilebilir.

Duplikasyon kistleri, düz kasla sarılmış, sindirim sistemi mukozası ile örtülü ve Gİ traktın herhangi bir segmentine yapışık oluşumlardır (8). Olgumuz duplikasyon kistinin tüm makroskopik ve histolojik karakteristiklerini barındırmakta idi.

Japonya'dan bildirilen 49 duplikasyon kistli olgu incelendiğinde, duplikasyon kisti görülme sıklığı açısından, kadın/erkek oranı 2.13/1 olarak tespit edilmiştir. Erişkin olgularda en sık semptomlar üst abdomen ağrısı (\%63), sıklıkla ektopik gastrik mukoza ile ilişkili gastrointestinal kanama (\%18) idi. Çoğu duplikasyon kistleri duodenumun 2. kitasından köken almakta idi $(\% 54,3)$ (9). Japon olgularla ilgili bu verilerin hepsi bizim olgumuzla örtüşmekte idi.

Erişkin çağda duodenal duplikasyon tanısı nadiren konmaktadır. Hastalığın nadir görülmesinin yanı sıra semptomların değisskenliği ve spesifik bir semptomun bulunmaması da tanıyı zorlaştırmaktadır. Literatürde abdominal ultrasonografinin ve bilgisayarlı tomografinin değerli tanısal yöntemler olduğu belirtilmektedir. Duodenal duplikasyon kistinin benign olması, lokal nüksü veya metastazı olmaması nedeniyle diğer duodenal veya paraduodenal kitlelerden ayrımı gerekmektedir. Kist duvarının görünümü ve peristaltik aktivitenin belirlenmesi açısından ultrasonografik değerlendirmenin tanı koydurucu özelliği bulunmaktadır. Bilgisayarlı tomografi preoperatif olarak kistin varlığının doğrulanmasında, büyüklük, lokalizasyon ve içeriğinin belirlenmesinde önemlidir $(10,11)$. Peristaltizm ayrıca endosonografi ile de gösterilebilir. Peristaltizmin gösterilmesinin tanı konmasında, ağrı patogenezinin anlaşılmasında ve kiste yaklaşımın belirlenebilmesi açısından önemi büyüktür (12).

Duodenal duplikasyon kistlerinin tedavisinde cerrahi ve endoskopik yöntemler kullanılabilir. Roux-en-Y pankreatikojejunostomi veya kistojejunostomi ile birlikte veya bunlar yapılmaksızın direkt olarak kist eksizyonu yapılabilir. Tedavide 
endoskopinin rolü ilk olarak 1984'te tanımlanmıştır. Duodenal obstrüksiyonun nedeni araştırılırken transduodenal kist eksizyonu uygulanmıştır. 1987'de ise polipektomi snare tekniği ile parsiyel duodenal duplikasyon kist eksizyonu uygulanmıştır. Endoskopik iğne bıçağı ve sfinkterotomi ile kistin

\section{KAYNAKLAR}

1. Ildstad ST, Tollerud DJ, Weiss RG, et al. Duplications of the alimentary tract: clinical characteristics, preferred treatment, and associated malformations. Ann Surg 1998;208:184-9.

2. Nagamine N, Miyagi Y, Endo I, Masa Y, Nohara Y. Alimentary tract duplications (in Japanese). Gekashinryo (Surg Diagn Treatm) 1977;19:46671.

3. Gross RE, Holcomb GW Jr, Farber S. Duplications of the alimentary tract. Pediatrics 1952;9:449-68.

4. Kawashima H, Iwanaka T, Matsumoto M, et al. Pyloric stenosis caused by noncystic duodenal duplication and ectopic pancreas in a neonate. J Pediatr Gastroenterol Nutr 1998;27:228-9.

5. Goi T, Katayama K, Hirose K, et al. A case of duodenal duplication and a review of reported cases (Article in Japanese). Nihon Geka Gakkaizasshi (J Jpn Surg Soc) 1995;96:399-401.

6. Ogura Y, Kawarada Y, Mizumoto R. Duodenal duplication cyst communicationg with an accessory pancreatic duct of Santorini. Hepatogastroenterology 1998;45:1613-8.

7. Whiddon DR, Olutoye OO, Broderick TJ, et al. Recurrent acute pancreatitis caused by a gastric duplication communicating with an aberrant pancreas. Am Surg 1999;65:121-4. duodenuma açılması günümüzde en kabul gören endoskopik metodlardır $(13,14)$. Kliniğimize başvuran duodenal duplikasyon kistli olguya ayrı 2 seansta iğne uçlu sfinkterotomi ve snare polipektomi yöntemleri uygulanmış ve sonuç başarılı olmuştur.

8. Ladd WE, Gross RE. Surgical treatment of duplications of the alimentary tract. Surg Gynecol Obstet 1940;70:221-45.

9. Shimada H, Nakagawara G, Nakano A, et al. A duodenal duplication cyst communicated with an accessory pancreatic duct. Jpn J Surg 1984;14: 320-6.

10. Procacci C, Portuese A, Fugazzola C, et al. Duodenal duplication in the adult: its relationships with pancreatitis. Gastrointest Radiol 1988;13:315-22.

11. FlØjou JF, Potet F, Molas G, et al. Cystic dystrophy of the gastric and duodenal wall developing in heterotopic pancreas: an unrecognized entity. Gut 1993;34:343-7

12. Bhatia V, Garg PK, Gupta SD, et al. Demonstration of peristalsis in gastric duplication cyst by EUS: implications for diagnosis and symptomatology (with videos).Gastrointest Endosc 2008;68:183-5.

13. Vandenbroucke F, Dagenais M, Letourneau R, et al. Endoscopic treatment of a duodenal duplication cyst. Endoscopy 2005;37:601.

14. Rockx MA, McAlister VC. Endoscopic fenestration of a duodenal duplication cyst to resolve recurrent pancreatitis. JOP 2007;8:795-8. 